\title{
SEX OFFENSES: A CLINICAL APPROACH
}

\author{
Bernard Glueck, SR.*
}

It is assumed in this article that a clinical approach to the problem of the sex offender based on genetic-dynamic considerations would add to our understanding of this problem. The material contained in this presentation has been familiar to students of the subject for a very long time, and a thorough acquaintance with it constitutes an indispensable part of the equipment of every competent psychiatrist. Very little, if anything, that is original or novel is added here, outside of the particular slant that this writer has given to its presentation. It is considered worthy of a restatement by this writer, who has been a student of the subject for over a half century, because the machinery of the criminal law still pays little or no attention to the clinical aspects of the problem as here considered. This article does not deal with the very important practical or theoretical issues that concern the recognition, apprehension, and criminal adjudication of the sex offender. It is to be expected, however, that it contains implicitly, at any rate, suggestions for preventive and therapeutic considerations.

Sigmund Freud, who contributed a great many challenging and pertinent observations on the sexuality of man, spoke of the manifestations of sexuality in the human infant as "polymorphous perverse." This may have been an unfortunate designation, as it undoubtedly offended the sensibilities of the cultural climate of his day and was responsible, to a large extent, for the hostile reactions to his views. Nevertheless, our understanding of the sexual deviations in the adult human being and his behavior, sometimes designated as a sexual offense subject to criminal prosecution, can be best understood, even today, when we consider them as infantilisms that have persisted into adulthood. It might, therefore, be worthwhile to review at this point in some detail Freud's sexual or holophilic theories, even though this has become more or less common knowledge.

We might begin by restating here some of the basic principles that underlie human conduct in all its aspects and that cannot be ignored in any attempt to understand and assess the conduct of any particular individual. These principles were stated with admirable clarity and precision by Masserman in a paper published some years ago. ${ }^{1}$ The first principle deals with motivation, and it states in elementary terms that every human being is basically motivated to survive and to propagate. The second principle points out that each human being reacts to the world about

- M.D. 1909, Georgetown University. Clinical Professor of Psychiatry, University of North Carolina. Author, Studies in Forensic Psychiatry (I9i6). Contributor to psychiatric and criminological publications.

1 Masserman, Mental Hygiene in a World Crisis, in Blo-dynamics of a World Mental Hyglene. (1949). 
him not as others view it, but as he himself interprets his surroundings in terms of his own capacities and individual experiences. The third principle reveals that when normal human adaptations are frustrated by external circumstances, man's behavior becomes deviated into substitutive channels, such as fantasy formations, retreats to immature patterns of conduct, or reactive hostilities and regressions. Finaily, the fourth principle asserts that when inner strivings become conflictful with each other and so make adequate external adjustments impossible, man's behavior becomes highly deviated, substitutive, regressive, and fantasy-ridden, or as we know it clinically, neurotic or psychotic.

Man being thus basically motivated to survive and to propagate, it might be assumed that each human being leads a dual existence-on the one hand, he is an entity in himself; on the other, an insignificant component of that large entity, his race or species. Accordingly, it is assumed that corresponding to these two roles, he begins life endowed with two great groups of indwelling tendencies, or impulses, or drives, or instincts, if you prefer-the one wholly egoistic or self-preservative, the other essentially altruistic and preservative of the race or species. Of the first group, hunger is the chief sense or sensory representative; of the second, the desire for sexual congress. Careful observation of the manifestations that go with ontogenetic stages in human development will demonstrate that these two great groups of indwelling tendencies lend themselves to a separation of those that might be called "hunger processes" and those that might be termed "sexual processes." Thus, all pursuits pertaining to comfort, shelter, and security would belong to the selfpreservative or egoistic drives in pursuit of both proximate or distant goals of satisfaction; while all those wishes that aim at self-adornment and the cultivation of attractiveness would properly be considered to belong to the sphere of sex. The term "sexual" thus acquires a much broader connotation, more of the meaning attributed to the word "love." It certainly was not meant by Freud to be limited to genital functioning as such.

Frink, as far back as $x 918$, proposed the use of the term "holophilic" instead of "sexual" for designating all kinds of affectional and love manifestations as related to the sexual instincts in the Freudian sense. ${ }^{2}$ The judicious employment of the word "holophilic" in place of "sexual" would serve to avoid some possible misunderstandings. In the realm of law enforcement, particularly, this substitute for the word "sexual" might prove of great importance. Many individuals have been prosecuted and punished, for instance, for voyeurism or exhibitionism, admittedly sources of sexual satisfaction, but involving no genital activity.

The great debate that has been going on for a very long time as to the extent to which psychiatry, especially in its dynamic aspects, can be of assistance in the administration of the criminal law will never be satisfactorily resolved until the law student, from the very beginning of his career, is exposed to and acquainted with the

${ }^{2}$ H. W. Frink, Morbid Fears and Compulsions: Their Psychology and Psychoanalytic Tineatment c. I (1918). 
clinical approach to human conduct. This applies naturally more to those who aspire to work in the field of the criminal law. Let us continue to pursue, then, our inquiry into those basic and indispensable phenomena of life that alone can furnish dependable guides for the intelligent administration of the problems of the sex offender, so called. We shall find in the course of this inquiry that the subject of the sexual life of man is being approached by two radically differing schools of thought-the orthodox Freudian school, which emphasizes the instinctual, unlearned aspects in the evolution and synthesis of the sexual functions; and the adaptational school, which stresses the conditioning and learning features in the sexual synthesis. Let us consider the Freudian view first.

Because the reactions to stimuli that the organism receives usually, if not invariably, represent outputs of energy entirely disproportionate to the amounts of energy impinging on the sense organs--that is, the energy of the stimuli themselves-two sets of instincts were postulated as sources of energy to account for this discrepancynamely, ego and sexual or holophilic instincts. In Freudian psychology, these are said to furnish the primary push and drive for the two great groups of processes or reactions into which the phenomena of individual life might be divided.

Frink, to whose important work we have already referred, has this to say by way of illustrating what is meant here. If, for instance, a photographic plate in a camera is exposed to the light rays coming from a grizzly bear, an impression is made on the plate that is directly proportionate to the amount of light and the length of time of the exposure. But if these same rays impinge on another sort of sensitized plate, say the retina of a human eye or that of another animal, there results an effect consequent upon fear or flight, the energy output of which bears no definite ratio to the energy content of incoming rays and is of infinitely greater magnitude. The role of the stimulus in this and in practically all other cases is that of releasing into kinetic expression an energy that was latent within the organism. To express this notion of latent energy, the concept of instinct has been introduced and is conceived to be the source of the energy that is liberated in response to various external and internal stimuli. In the case of the holophilic group of phenomena, the term "libido" was given by Freud to the energy thus released. The term "libido" and the complex theory of which it is the symbol has been the subject of much controversy, and some students prefer as a substitute the word "horme," as proposed by Jung. ${ }^{3}$

The question of latent or stored energy that is subject to conversion into kinetic energy is closely related to the question of instinct in human conduct, concerning which there has been much controversy in the behavioral sciences. It might be well, therefore, to devote some brief discussion to it here, since this article is directed largely to an audience presumed not to be concerned primarily with issues dealt with in the behavioral sciences. The writer is considering here some of the contributions of the

${ }^{3}$ Jung, On Psychological Understanding, 9 J. Aswormal Psxch. 385 (I914-I5). 
late Charles Mercier, who dealt with this subject in great detail. ${ }^{4}$ Referring to the organism's inner store of energy, he stated: "The aimless jerkings and sprawlings and crying of the new-born infant are due, or need be due, to no irritation or stimulus from without, but to a liberation of pent-up motion from within." Such movements fall short of acts, it is true. They can scarcely be called purposive, and yet, in a sense, they are purposive. They serve the purpose of getting rid of some of the stored motion that has accumulated to excess.

In the more developed and adult human being, the opening of the eyes on spontaneous waking in the morning, the throwing off of the clothes, and the getting out of bed are due not to a stimulus from without, but to the liberation of motion from within. To the vigorous body, there comes a time when retention of stillness becomes irksome, becomes impracticable and, one might add, nonadaptive. For instance, the writer after several hours at his desk, the traveler after several hours on the train, must rise and stretch his limbs, must get out and pace the platform not because he is excited or attracted to do so by any external allurement, not because he is compelled by any external disturbance, but because motion has accumulated within him to a point of tension that overcomes the resistance opposed to it. No fresh man in the vigor of health can content himself with doing nothing. If there were no such (internal) store of motion (and its accumulation), there would be no conduct, no action. Thus it is true, at the top as well as the bottom of the scale, in man as well as in the amoeba, that the primary initiation of conduct, and the possibility of conduct, is the accumulation within the organism of a store of motion that imperatively demands expenditure.

Mercier wrote at the turn of the century, and the views he held concerning the nature of human conduct must be considered in that light. Nevertheless, they are still valid today with respect to the nature of the economics of energy of the two basic desires of which we spoke earlier. He goes on to say: "Two partial, and as I think, erroneous views of action are in vogue. There is a school which traces all conduct back to a root in reflex action." With this doctrine, Mercier profoundly disagrees. Action has two roots, of which reflex action is but one, and the less important. The mainspring of conduct is not reflex action, but spontaneous action, that expenditure of stored motion that is not elicited by the applications of stimulus, but is the inevitable result of accumulation to a degree of tension that breaks down resistance. There is a large department of conduct, for instance, known as recreative, that owes its origin to the necessity of expending accumulated motion and cannot be accounted for by the stimulus of circumstances.

The other view of action ascribes its origin to volition and finds in the will of the actor a complete explanation of conduct. From this view also, Mercier dissents. From the biological point of view, conduct is the product of two factors, the internal factor and the external factor, and this double origin must be taken into account if

* Charles Mercier, Conduct and Its Disorders, Brologically Considered (1913). 
we are to understand the problem we are considering here-namely, the problem of the sex offender.

To quote Mercier again:

We act, and as all acts are movements or arrests or suppression of movements, in order to act we must be able to move, that is, we should have at our command a store of motion susceptible of expenditure. And we act, not in vacuo, but in a world of circumstance; and, in order that we may so act, it is necessary to take account of circumstances, it is necessary that we should respond to the impress of circumstances.

Without a store of motion, there could be no movement, and, therefore, no action. and no conduct, since conduct is action; without a response to the impress of circumstance, there could be no adaptation of action to circumstance, and, therefore, no conduct, since conduct is the pursuit of ends by modifying circumstances. All action is due to the cooperation of these two and is controlled, guided, varied, and determined by the combination of the internal factor with the external factor. The initiation of action may be due to the internal factor, to the external factor, or to a combination of the two, and the continuance or cessation of action is similarly. determined.

Not only may the initiation, continuance, or cessation of action be determined. by either the internal or the external factor, or by a combination of the two, but thedirection that the action takes may also be determined in either of these two ways, and this leads us to the cardinal distinction between instinctive and reasoned: action.

This digression from the basic theme and objective of this article, which we undertook at the point of considering the discrepancy between input (as stimuli) and output (as reaction), was considered justified, even though it might be said: to deal with trite matter, in order to help us understand some of the more obscureelements in Freudian theory, upon which a good deal of the criticism of the adaptational school is based.

We shall now go a step further and examine the theory of instinct by thephenomenologist Mercier, upon whom we have already leaned extensively. Let us. select one or two examples from the many that he cites in order to validate his thesis. of the nature of human conduct. In considering the relation of reasoned to instinctual conduct, he states that as the conduct of animals is not wholly instinctive, but always, at least in its higher manifestations, contains some element of reason, so the conduct of man is not wholly reasoned, but contains always some element of: instinct. In the lower animals, the internal factor greatly predominates, and little margin is left for the choice of means to attain the end that the instinct dictates. In: man, the reasoned factor encroaches more and more in discovering means to attain his ends, but the ends, the ultimate ends, are always instinctively determined. In contemplating the conduct of man, we are in the habit of regarding mainly the means by which he achieves his ends, and when we take account of purposes, we regard? 
mainly the proximate and intermediate purposes, which, as well as the intermediate means, may be dictated by reason; and thus we are apt to regard the whole conduct of man as reasoned and neglect those fundamental and underlying purposes that are not reasoned, but instinctive. In truth, and upon close examination, it is found that instinct is no more excluded from the conduct of man by the prevalence of reason than reason is excluded from the conduct of animals by the dominance of instinct.

In lower animals, instinct dictates not only the end, but also, to a considerable extent, the means by which the end is achieved, and leaves but a margin, large or small, to the guidance of reason. In man, instinct dictates the main ends only, and the reasoned margin is so greatly increased that it seems to occupy the whole area; but it does not. The man of science who conducts some prolonged investigation for the solution of a difficult problem-say, in physics or biology-immerses himself in operations of the most highly reasoned character, but these highly reasoned operations are means merely to the attainment of some end that is dictated by some imperious instinct. Is he working for ultimate pecuniary reward? The dictation of instinct is manifest. Does he work for fame? The desire for fame is a high development of that desire for the esteem of one's fellows, which is the common instinctive possession of all men. Does he work for the pure love of investigation and to find out the secrets of nature? Then he is actuated by the same instinct of curiosity that prompts the girl to disarticulate her doll, the boy to rip up the bellows and pull his watch to pieces; that draws the deer to the decoy, the magpie to the jewel, the salmon to the torch, the moth to the lamp.

It would be desirable on this occasion to present more fully Mercier's views on instinct, particularly what he has to say about the fossilization of reason into instinct and the liquidation of instinct into reason. We must, however, return to the examination of the evolution and synthesis of the sexual instinct in man as viewed by orthodox Freudian psychoanalysis. We stated earlier that an understanding of the development of mature sexuality out of the polymorphous perverse state of infantile sexuality is indispensable for a dependable understanding of the sexual deviations and perversities of the adult sex offender.

One of Freud's great achievements was the demonstration that the sexual instinct as first manifested at the time of puberty is not a new characteristic, but a synthetic product, so to speak, formed by uniting certain of a number of holophilic trends or impulses that were present throughout childhood, thus demonstrating that the germs of sexuality are present in the individual from his very birth. When it is remembered that all the receptor surfaces, all the complicated systems of voluntary, sympathetic, and autonomic arcs and end-organs involved in the reactions represented by the love life of the adult are present in practically their fully developed form long before the beginning of puberty, the hostile reactions to Freud's views about sexuality in infants and children cannot be understood on any realistic or scientific grounds. The evidence about the changes at puberty points not to the 
introduction of new arcs or to old ones suddenly becoming permeable, but rather to the maturing of certain glands that now begin to pour their internal secretions into the blood stream and in the male furnish a new substance for external discharge. Frink points out that it would be hard to believe all this complicated machinery waited silently and idle, or was responsive only to nonsexual stimuli and capable only of nonsexual reactions during all the years preceding puberty and this new glandular activity. On the contrary, it would be logical to expect the occurrence of many and complicated reactions, lacking, to be sure, something possessed by the sexual processes of the adult, but, nevertheless, fully deserving to be called sexual. By what form of reasoning are we justified in assuming that sexuality develops de novo at puberty, rather than that the advent upon the scene of the secretions of certain glands adds further power and emphasis to an already existing complicated machinery of structure and function present from birth and freely reacting before the attainment of sexual maturity.

In Freudian theory, there are three phases to the sexuality of the human being: (I) an infantile or preinhibitory period, which corresponds to the first three or four years of life; (2) the childhood or latency period, which succeeds the first and ends with puberty; and (3) the adult period, sometimes designated as the period of object-love. The criticisms directed at these assumptions by the adaptational school would be less justified and certainly less virulent if it were remembered that the instinctual basis assumed for these developmental phases refers to ends, and not to the means for achieving them. These means or ways of achieving the ends of instinct are adaptational in nature and take into consideration differences of personality and of circumstances.

The sexual or holophilic phenomena of the first period consist chiefly in the pleasurable sensations that the infant derives from the stimulation of certain sensitive areas that are known as erogenous zones. These zones are represented by the oral, anal, and urethral orifices, the penis in the male, and the labia and clitoris in the female. The first pleasurable stimulations from them are incidental to the performing of the functions of alimentation. In the infant, the pleasure derived from the taking of nourishment is not attributable solely to the pleasures of taste and the actual satisfaction of the craving for food; the tactile and kinesthetic sensations created during the act of sucking, too, are distinctly agreeable and pleasurable in themselves. In the same way, the voiding of excrement not only represents the relief from the discomfort of not voiding, but also gives rise to tactile and and muscular sensations that have a definite pleasure value in themselves. Having experienced these pleasurable sensations incident to the performing of the alimentary functions, the infant soon seeks to re-experience them for their own sake. The almost universal habit of sucking of the thumb or other objects is well known. Similarly well known, and perhaps as common, is the retention of feces and refusal to empty the bowel when placed upon the toilet until there is an accumulation of sufficient size and consistency to give the act of evacuation the greatest possible amount of pleasure. 
The reason these phenomena are classed in the sexual or holophilic group, and not in the class of tendencies that belong to the self-preservative or ego functions, is because of their later history. The orally-centered perversions or perversities of the adult, such as fellatio and cunnilingus, can be understood best as direct descendants of the infantile pleasure-sucking, which in most cases of the adult pervert had been indulged in with great fervor and continued for a long time. In line with the requirements of an adaptational approach, we must postulate in these cases differences in circumstances of the infant's milieu and difference in the makeup of the infant.

But the psychoanalytic study of certain neurotic manifestations in the adult, such as hysterical vomiting and some food idiosyncrasies, are justly looked upon in many instances as reaction formations or defensive maneuvers against similar oral-erotic longings and phantasies that have now become offensive and unacceptable to the controlling trends of the personality. The oral-eroticism of the infant is represented in the normal adult as the pleasure in kissing. Naturally, these rudimentary holophilic activities of the infant cannot be expected to be in every particular like those of the adult. Kissing in the adult excites the genital system, while the sensations excited in pleasure-sucking remain local. Here, the intercommunication of the various holophilic impulses-that is, the sexual synthesis-has not yet been established, for the reason that the glands whose internal secretions are largely instrumental in its accomplishment have yet to mature. Nevertheless, the infantile eroticism as exemplified in pleasure-sucking is not set off as sharply from adult sexuality as one might perhaps expect. In certain rather exceptional cases, at least, it proceeds to an orgastic climax, succeeded by a period of complete passivity and relaxation, the whole phenomenon bearing such a striking similarity to the sexual acme and immediately subsequent relaxation in the adult that it could hardly escape the observer.

The first stimulations of the penile and clitoral zones appear to result either from irritation produced by discharged secretion or excretion in contact with them, or from the manipulation involved in keeping the child clean. These pleasurably experienced stimulations the infant then seeks to repeat by either thigh-rubbing or the use of the hand. The former seems to be more common in female infants, the latter, in males. All the erogenous zones in infancy have, at least to begin with, about the same degree of pleasure sensibility. As development proceeds, the significance of one zone may be accentuated over that of the others through repeated stimulation, but there is nothing corresponding to the primacy that in the normal adult the genitalia achieve over all other regions of the body. Furthermore, it should be kept in mind that the different zones ordinarily remain perfectly independent of one another; excitement of one does not of itself produce an excitement of heightened sensibility in any of the others, as happens in the adult when, for instance, the oral zone is stimulated and the phenomena of sexual excitement occur in the genitals without their being stimulated directly. 
In addition to the zonal components of the holophilic instinct, there appears a little later a set of impulses that have at first no connection with the erogenous areas. These so-called partial impulses go in pairs, of which one is active and the other passive. One of these pairs is the sadistic and masochistic impulse. The former consists of an aggressive tendency and is manifested as a desire to dominate, to use force, roughness, or violence, and if it reaches an extensive degree, to inflict pain. The masochistic tendency has just the opposite nature and is shown as a pleasure in obedience, submission, and the enduring of humiliation or pain.

Another pair of partial impulses consists of the impulse to showing (exhibit) and looking-the former being passive and the latter, active. They refer not only to the genitals themselves, but to the entire body. Out of a union of the looking impulse, with a contribution from the acquisitive trend of the self-preservative group, there arises the curiosity impulse. The impulses to touch and to be touched, etc., belong in the same group of partial desires.

These partial impulses, desires, or perhaps even indwelling needs are readily identified as forerunners of tendencies apparent in the sex life of the normal adult. The sadistic impulse, for instance, corresponds to the normal aggressiveness in courtship shown by the male in comparison with the female, his inclination to master, and occasionally to be rough with the loved object.

It must be pointed out, however, that these partial impulses represent rudiments corresponding not only to tendencies normally present in adult life, but also to those of certain perversions, sadism, masochism, exhibitionism, voyeurism, etc. In fact, there is a perversion corresponding to each one of the partial impulses of infancy. The same may be said with regard to the zonal components. This is the reason that led Freud to designate the infantile sexuality as "polymorphous perverse"-unfortunately so, because there is really nothing perverse about these infantile manifestations at all. True perversion results only when those trends experience a disproportionate development and fail to become subordinated to the genital zone at the time of the sexual synthesis at puberty. The conspicious feature of the sexuality of the infantile period, however, and for that matter, in the belief of some, of the childhood period also-is that it is predominantly autoerotic. The child gains his satisfaction, for the most part, from his own body; he is not dependent, as is the adult, upon a second person for the satisfaction of his holophilic needs. In the normal adult's love life, the sexual object, this other person, is indispensable; the sexuality of the infant is, for the most part, objectless.

Like most tenets of the Freudian contributions, the above statement should not be taken without some qualifications. The predominance of the autoeroticism in childhood is not absolute. Some observers claim that even as early as the beginning of the second year of childhood, rudimentary manifestations of object-love can be observed that foreshadow, and in a sense are the model for, that great factor in adult life. 
This is a restatement, in considerable detail, of observations concernings man's infancy that are common knowledge among those concerned with these issues. These observations have been reiterated in the literature with an endless repetition that at times becomes boresome because of its monotony. And while there still exists some diversity of opinion concerning the meaning of these childhood manifestations -particularly whether they are in a sense preordained, so to speak, or manifestations of an adaptational conditioning, of a learning process-their relationship to future manifestations in adult life has been generally accepted.

For a better understanding of the issues with which we are concerned herenamely, the problem of the sex offender and how to deal more effectively than heretofore with this problem-it is indispensable that we restate here in detail these elements of the drama of acculturation or social-psychological conditioning that constitutes the matrix out of which the grown-up individual evolves. Whether the product will be a socially mature, responsible, and dependable individual, integrated in a stable organization, or whether the opposite of this model of a normal human being will result can still be most reliably predicted from the careful study of these early phenomena of the life of infancy and childhood and the conditions and circumstances under which this early life had been lived. We shall, therefore, continue to deal with this material as though it is addressed primarily and essentially to the student of human behavior, no matter into what sphere of human conduct he is obliged to apply himself.

Thus, the first extra-egoistic holophilic interests of the infant direct themselves to persons in the infant's immediate environment, parents, nurses, etc., but the libido, or holophilic energy, is distributed in unequal quantities to these individuals, so that in normal children, there is soon revealed a preference for the opposite sex. Thus, the little boy loves the mother more than he does the father, while with the little girl, it is the father who is the preferred love-object. Quite generally and very early, the parent of the same sex as the child is looked upon as an interferer and a rival for the affections of the parent more greatly loved. The little boy, for instance, wishes that his father were out of the way so that he could have his mother all to himself. Sometimes, the irksome presence of the father generates a wish for his death, but this idea does not generate the horror that it does in the adult because in the child, the idea of death is equated with the idea of "gone away." This early object-selection forms the foundations for those important constellations-namely, the Oedipus complex in the male and the Electra complex in the female, which in the eyes of the unbiased observer are of great significance not only in the later life of the neurotic, but in that of normal people as well, and have been designated the "nuclear complexes."

In these alloerotic phenomena, as distinguished from the essentially autoerotic processes that constitute the major portion of the infantile holophilic reactions, the nearest approach is made to the phenomena of love in the adult. The essential difference is the lack of synthesis of the various impulses into any definite pattern or 
hierarchy such as exists in normal adult life. That is to say, all the impulses remain as separate and independent sources of pleasure; the significance of the genital zone is not, as in the case of the normal adult, accentuated over that of all the others, and the partial impulses are not intimately connected with it. For instance, in the adult, the gratification of one of these partial impulses-say, the desire to touch the love-object-although in itself a source of pleasure, creates in addition a desire for greater pleasure, that of coitus. Thus, the two stand in relation to each other of forepleasure and endpleasure. In infancy, there is no differentiation into pleasures of different order. All the holophilic pleasures are endpleasures, and whatever organization that may exist among the various impulses is a pregenital organization. The several pleasures of this period are, for the most part, lacking in the genital component, unless the genitals are directly stimulated.

Because of what has been said about the Oedipus and Electra complexes and the heterosexual nature of the child's first object-libidinal stirring, it should not be assumed that all the child's holophilic interest is directed towards the opposite sex. On the contrary, a bisexual, or, to use Ferenzi's term an "amphierotic" tendency is apparent. Some of the libido takes a homosexual direction, being applied (in the boy) to the father, brothers, or other males in the family. This homoerotic, homophilic, or homosexual direction of the libido in infancy corresponds to the normal friendships and attachments for one's own sex in the normal adult, and, in the abnormal, to the homosexual perversion.

These holophilic trends and activities of the infantile period reach a high point somewhere between the third and fifth years of life. Then, there begins a period of latency relatively complete in some individuals, but broken through in various degrees of expression of sexuality in others. The period of latency is initiated by the first appearance of such reactions as shame, modesty, disgust, sympathy, etc. They are the foundation and forerunners of all those ethical and esthetic trends that play the role of inhibitions upon the later sexual life and, like dikes or dams, narrow the avenues of holophilic expressions. The first appearance of these inhibitory tendencies is spontaneous, and if we look upon the idea that ontogeny recapitulates phylogeny as in some sense valid, these early reactions to the infantile preinhibitory holophilic manifestations may have some roots in the organic aspect of the maturation process. The further development and intensification of these inhibitory trends, however, depends in great measure for their extent and direction upon the culture and educational influences of the environment. The adaptational explanations of the important happenings during the latency period have to be considered in the light of Freud's remark that education remains properly within its assigned realm only if it strictly follows the path sketched for it by the spontaneously-appearing inhibitory tendencies and limits itself to emphasizing and developing these. We know from clinical observation of those instances where the well-meant educational and corrective efforts of parents overstepped the limits indicated by the spontaneous inhibitions and 
went too far in some directions, thus producing an ultimate effect upon the child that was very different from the beneficial one intended.

The controlling forces that are thus shaped by educational and training influences and that eventuate in an apparent, more or less complete disappearance of the infantile sexuality as manifested in the first period are, in large measure, developed at the expense of the infantile sexuality and derive much of their motive power from it. For instance, the masochistic partial impulse furnishes the motive for obedience and leads the child to accept and to embody into his own personality the codes or standards of those about him. Similarly, the exhibitionistic impulse, manifested at first in the desire to have the body looked at, later expresses its energies in whatever action may serve to win parental approbation and praise. In other words, the energy of these impulses may eventually lead the child to avoid acts by which he gratified them originally. In this manner, the control and suppression of the primitive infantile sexuality is, in large part, accomplished by motives derived from the infantile sexuality itself.

Evidence emerges also of the capability of the libidinal energies to become modified, redirected, and subject to quantification. The libido directed toward the members of the family or other persons of the environment tends more and more to be displaced from the sexual aims of the first period and to depart from manifestations coinciding with the popular meaning of the word "sexual," taking on an aspect that coincides with the meaning of the word "love" in its narrow sense-that is to say, affection. The love of the mother thus loses whatever crassly sexual appearance it might at first have possessed, while the infantile hostility and jealousy exhibited towards the father may disappear from view entirely or be represented only as a diffuse inclination to disobedience, dislike of authority, etc. In other words, the manifestations of the Oedipus complex undergo a profound amelioration.

This refining process, through which the energies of the primary components of the sex drive are divorced from their original aims and are now being applied to new aims and activities of a higher and socially more valuable order, is not limited to the formation of controlling or inhibiting trends as just described, which, in large méasure, represent the basis for estheticism and morality; it also occurs in other connections. The primitive sexual curiosity thus becomes a desire for general knowledge; the sadistic impulse finds expression in self-assertiveness and as a desire to win or excel in games, sports, or any other sort of competition, etc. Such employment of the primitive energies for higher aims is known as sublimation.

The latency period, as has been said, is by no means always complete, and in many individuals, it is occasionally or even constantly broken through by some form or other of definitely sexual manifestations. In children in whom this takes place extensively, it often may be interpreted as the foreshadowing of a later neurosis or sexual abnormality.

A wholly normal suspension of latency manifestations occurs with the onset of puberty, and with it, the latency period is terminated. The holophilic instinct 
now changes from its infantile to its adult form. Hitherto, its manifestations have been predominantly autoerotic; now, begins the predominance of object-love. Hitherto, the various partial impulses and zonal pleasure sources existed, for the most part, side by side in a sort of democratic equality; now, they become organized into a hierarchy. The genital zone acquires a primacy over all the other components of the holophilic impulse, or drive, or instinct, and under normal conditions, everything else is subordinated to this primacy of genitalism. The partial impulses, looking, touching, sadistic aggression, etc., and their passive counterparts, and the oral or other zones still susceptible to sexual stimulation now fall into the subordinate role of forepleasure sources of gratification, and the entire forepleasure machinery now serves the unified purpose of preparing for and urging towards the final holophilic act through which sexuality becomes articulated with the function of procreation in the endpleasure of coitus. Autoerotism, although in most cases holding its ground for a time in the form of the masturbatory activities that ordinarily appear about the time of puberty, is gradually replaced by the new regime of object-love.

Under normal circumstances, libido is eventually withdrawn from its affectionate fixation upon members of the family and their surrogates, and charged with the new qualities of glandular influence, it is at length transferred to extrafamilial individuals of the opposite sex with whom, as foreshadowed in the masturbation fantasies of puberty, a complete love life can eventually be carried out. Only with the complete synthesis that takes place at puberty do the normal differences between the sexuality of the male and the female come into high relief. The active or aggressive trends come to predominate in the character of the male; the passive, in the female. Incidentally, it may be remarked that the change at puberty from infantile to adult sexuality is more sharply marked and more sudden in the male than in the female. The love life of the female retains in perhaps most cases a good deal of the character of infantile sexuality all through adolescence and quite often well into or even throughout adult life.

This sketch of what is considered in orthodox psychoanalytic psychology the formal ontogenesis of the holophilic or sexual instinct in man is an indispensable prolegomenon to an understanding of the many ways in which there may occur in the sexual life of man the distortions, deviations, and perversities that constitute the raw material of the potential sex offender, legally considered. Every step in the ontogenetic development of sex in man, every transition that must be passed through, offers possibilities of morbid disturbance, through a persistence of this or that phase that should have normally been passed, through the opening up of avenues of aberrant development, or through the formation of a locus minoris resistentiae, or weak spot, at which the apparently normally accomplished sexual synthesis may give way under the strain and stress of adult life. 